\title{
Potentiometric sensor for iron (III) quantitative determination: experimental and computational approaches
}

\author{
Somayeh Badakhshan ${ }^{1,2}$, Saeid Ahmadzadeh ${ }^{3,4^{*}} \mathbb{C}$, Anoushiravan Mohseni-Bandpei ${ }^{5^{*}}$, Majid Aghasi ${ }^{6}$ \\ and Amir Basiri ${ }^{7}$
}

\begin{abstract}
The current work deals with fabrication and validation of a new highly $\mathrm{Fe}^{3+}$ selective sensor based on benzo-18crown-6 (b-18C6) using the potentiometric method. The proposed sensor revealed satisfactory performance for quantitative evaluation of $\mathrm{Fe}^{3+}$ trace amount in environmental samples. The ratio of membrane ingredients optimized and the membrane with the composition of 4:30:65.5:0.5 mg of b-18C6:PVC:O-NPOE:KTpCIPB exhibited the desirable Nernstian slope of $19.51 \pm 0.10$ ( $\mathrm{mV}$ per decade of activity) over the $\mathrm{pH}$ range from 2.5 to 5.7 with an acceptable dynamic concentration range of $1.0 \times 10^{-6} \mathrm{M}$ to $1.0 \times 10^{-1} \mathrm{M}$ and lower detection limit of $8.0 \times 10^{-7} \mathrm{M}$. The proposed sensor demonstrated an appropriate reproducibility with a rapid response time of $12 \mathrm{~s}$ and the suitable lifetime of 10 weeks. To validate the accurate response of the proposed sensor, AAS technique applied for the determination of $\mathrm{Fe}^{3+}$ in real aqueous mediums such as drinking tap water and hospital wastewater sample after treatment by electrocoagulation process. Theoretical studies carried out using DFT/B3LYP computational level with 6-311G basis set to optimize the adsorption sites of $\mathrm{Fe}^{+3}$ cationic species by b-18C6. The obtained adsorption energy with large negative value confirmed the formation of a stable complex.
\end{abstract}

Keywords: Iron (III) sensor, Environmental analyses, Benzo-18-crown-6, PVC membrane, Potentiometry

\section{Introduction}

Iron as a heavy metal and its compounds extensively distributed in nature at various concentrations and play an important role in biological systems, especially electron transfer cycle [1-3]. Iron could pass into aqueous mediums via various procedures such as discharging of wastes, chemical corrosion of pipe which applied in the water distribution system as well as produced coagulants through electrocoagulation process using iron electrodes for the treatment of water. Iron deficiency caused anemia, while its high levels create hemochromatosis disease

\footnotetext{
*Correspondence: chem_ahmadzadeh@yahoo.com; a.mohseni8@yahoo.com

${ }^{3}$ Pharmaceutics Research Center, Institute of Neuropharmacology, Kerman University of Medical Sciences, P.O. Box: 76175-493,

76169-11319 Kerman, Iran

${ }^{5}$ Department of Environmental Health Engineering, School of Public Health, Shahid Beheshti University of Medical Sciences, Tehran, Iran Full list of author information is available at the end of the article
}

[2]. Iron speed up the growing of iron bacteria which get their energy from the oxidation of ferrous iron to ferric form that caused the deposition of a coating of viscous on the surface of the pipe [4]. Therefore, evaluation of iron content in the aqueous medium and developing the diagnostic tools for quantitative determination of its trace amount received extraordinary attention.

Various methods for determination of iron developed including catalytic spectrophotometric flow injection analysis [5], colorimetry [6], spectrophotometry [7], liquid-liquid microextraction [8], and ion selective electrodes $[1-4,9]$. Using ion-selective electrodes (ISEs) provides a valuable tool for the determination of the specific ionic target concentration with the simultaneous existence of interfering ionic species in the aqueous medium [10]. It is noteworthy to mention that compared to instrumental techniques the new developed ISEs offer much cheaper analysis with satisfactory dynamic concentration range and detection limit $[11,12]$. Due to the 
considerable advantages of ISEs including simple preparation and application, superior reproducibility with high selectivity and high-speed response, they received high attention for environmental, agricultural and industrial analysis [13-15].

Crown ethers; received extraordinary attention by many research groups as an important category of macrocyclic host molecules for the last two decades. Benzo-18-crown-6 is a versatile receptor with a threedimensional structure which makes it capable to form a stable complex with high selectivity and efficient binding properties towards $\mathrm{Fe}^{3+}$ as the target ion [16, 17]. Hostguest chemistry of benzo-18-crown-6 which makes it a suitable ionophore for constructing the current potentiometric sensor includes the weak and reversible nature of non-covalent intermolecular interactions with $\mathrm{Fe}^{3+}$ ions through coordination bonds between the donor atoms of oxygen with the $\mathrm{Fe}^{3+}$ ions, as well as $\pi$-coordination of the $\mathrm{Fe}^{3+}$ ions with the benzene ring [18] (see Fig. 1).

It is noteworthy to mention that, the polymeric membrane is the most considerable issue in fabrication of ion selective electrode. It consists of polymeric matrix, ionophore, plasticizer and lipophilic additive. The polymeric membrane physically separates the internal filling solution from the sample solution and it is the source of the signal generated by the ISE. The nature and amount of each component have a significant effect on the characteristics performance of the ISE.

Many polymers have been utilized as a matrix in fabrication of ion selective membranes which provide considerably good mechanical strength properties and structural integrity for the membrane [19]. High molecular weight polyvinyl chloride (PVC) with high glass transition temperature $\left(\mathrm{Tg}=80{ }^{\circ} \mathrm{C}\right)$ is a brittle polymer at ambient conditions, hence using of plasticizer is unavoidable to reduce the value of the Tg. The ionophore is a macrocyclic compound which can selectively bind to the target ion and act as ion carrier for transferring ions from aqueous phase into the polymeric membrane phase. The complex formation constant between ionophore and



Fig. 1 Chemical structure of benzo-18-crown-6 target ion must be high enough to provide a complex with considerable selectivity in membrane phase. However, the value of the mentioned constant should not be so large in order to avoid the formation of kinetically irreversible complex [20].

Plasticizer plays an important role on optimizing the physical properties of the membrane by reducing the high glass transition temperature of PVC, as well as increasing the mobility of the active species and enhancing the flexibility of the polymer chain [21]. Also, it provides a good ionic conductivity under the ambient conditions which allow the diffusion of the membrane components into a homogenous lipophilic environment. Moreover, the nature of plasticizer significantly affected the selectivity and measuring range of ISEs [22]. It is known that the addition of proper lipophilic additive to membrane demonstrates a significant improve in the characteristic performance of ion selective electrode such as selectivity, stability and response time. Besides, it reduce the membrane impedance [20]. Even though the presence of ion exchangers in the membrane provides beneficial effects, but the excess amount of it declines the electrode performance [23].

The literature review revealed that the recently developed iron (III) selective electrodes suffered from undesirable characteristics such as low selectivity with narrow solution $\mathrm{pH}$ range as well as limited concentration range and lengthy runtime $[1-4,9]$. Therefore, herein, a new iron (III) selective electrode with satisfactory characteristic performance developed and successfully applied for evaluation of iron (III) content in various aqueous mediums.

\section{Experimental \\ Reagents}

All chemicals are analytical grade and used without any additional refinement. Polyvinyl chloride (PVC) with high molecular weight, benzo-18-crown-6 (b-18C6) and all investigated salts (nitrate and chloride) purchased from Merck company. Sodium tetraphenylborate (NaTPB), 2-nitrophenyl octyl ether (o-NPOE), tetradodecylammonium tetrakis(4-chlorophenyl)-borate (TDATpClPB), nitrobenzene (NB), Dioctyl phthalate (DOP), potassium tetrakis(4-chlorophenyl)borate (KTpClPB), dibutyl phthalate (DBP), tetrahydrofuran (THF), and sodium tetrakis [3,5-bis (trifluoromethyl) phenyl] borate (NaTFPB) obtained from Sigma-Aldrich, and Scharlau company. For $\mathrm{pH}$ adjustments, hydrochloric acid $(\mathrm{HCl})$ and sodium hydroxide $(\mathrm{NaOH})$ used. Hydrogen peroxide $\left(\mathrm{H}_{2} \mathrm{O}_{2}\right)$ which used as an oxidant to oxidize $\mathrm{Fe}(\mathrm{II})$ to $\mathrm{Fe}(\mathrm{III})$ in real samples purchased from Merck. De-ionized water used to prepare all daily solutions. 


\section{Apparatus and potential measurement}

Metrohm $827 \mathrm{pH} / \mathrm{mv}$ meter applied for the potential measurements using Metrohm $\mathrm{Ag}, \mathrm{AgCl} / 3 \mathrm{M} \mathrm{KCl}$ reference electrodes and Mettler Toledo $\mathrm{pH}$ electrode at $25{ }^{\circ} \mathrm{C}$. A Varian Atomic Absorption Spectrometry (Model AA240) and Optizen UV-Visible spectrophotometer (model 3220UV) employed for validation of sensor response and evaluation of complex reaction between the ionophore and iron (III), respectively. SEM (Philips model XL30E SEM) and FT-IR (Bruker model Alpha) were used to validate, identify and characterization of the synthesized membrane. A de-ionized water system (Smart2Pure model TKA) to supply water requirements was used throughout the study. The following electrochemical call employed for EMF measurements:

$\mathrm{Ag} / \mathrm{AgCl}$ ref. electrode, $\mathrm{KCl} \quad\left(\begin{array}{ll}3 & \mathrm{M}) \| \text { sample }\end{array}\right.$ solution $\mid$ selective polymeric membrane $1.0 \times 10^{-3} \mathrm{M}$ $\mathrm{Fe}\left(\mathrm{NO}_{3}\right)_{3}$ standard solution $\| \mathrm{Ag} / \mathrm{AgCl}$ ref. electrode, $\mathrm{KCl}(3 \mathrm{M})$.

\section{Electrode and real sample preparation}

The amount of $4.0 \mathrm{mg} \mathrm{b}-18 \mathrm{C} 6,30.0 \mathrm{mg}$ PVC, $65.5 \mathrm{mg}$ $\mathrm{o}-\mathrm{NPOE}$, and $0.5 \mathrm{mg} \mathrm{KTpClPB}$ dissolved in $3 \mathrm{ml}$ THF to prepare the polymeric membrane. The prepared solution concentrated until a viscose mixture achieved and afterward employed for preparing a polymeric membrane with the thickness of $0.3 \mathrm{~mm}$ at the end of the Pyrex tube with $3 \mathrm{~mm}$ i.d that finally filled with the $1.0 \times 10^{-3} \mathrm{M}$ $\mathrm{Fe}\left(\mathrm{NO}_{3}\right)_{3}$ standard solution.

To analyze the drinking tap water and hospital wastewater which treated through the electrocoagulation process, the standard addition method applied. For oxidizing iron (II) into iron (III) a mix of $5 \mathrm{~mL} \mathrm{H}_{2} \mathrm{O}_{2}$ and $5 \mathrm{~mL}$ of $\mathrm{HNO}_{3}$ both $1 \mathrm{~N}$ added to the real samples.

\section{Computational methods}

Theoretical studies carried out using DFT/B3LYP computational level with 6-311G basis set to optimize the adsorption sites of $\mathrm{Fe}^{+3}$ cationic species by b-18C6 using the Gaussian 09 program package. Natural bond orbital (NBO) analysis carried out to investigate the strength and nature of the intermolecular interactions of the formed complex. The charge distribution on the structure of the formed complex investigated.

\section{Results and discussion}

Potentiometric Response and membrane optimization process

The responses of the proposed sensor towards various ions investigated over the wide concentration variety and showed in Fig. 2. The obtained results indicated a preferred complex formation between b-18C6 and Fe(III) in comparison to the other investigated ions with the
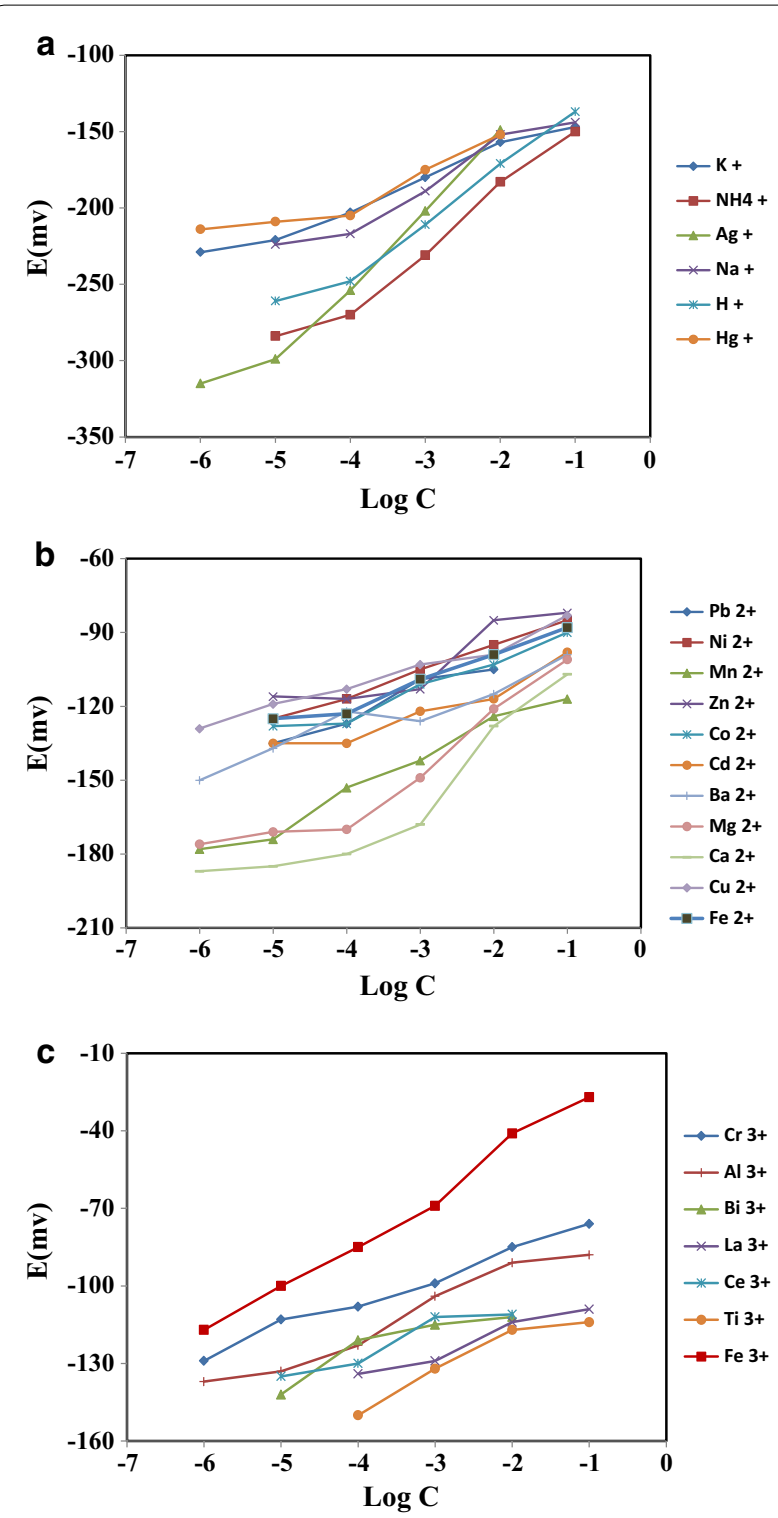

Fig. 2 The potential responses of PVC membrane sensor based on b-18C 6 towards monovalent cations (a), bivalent cations (b), and trivalent cations (c) at $25^{\circ} \mathrm{C}$

satisfactory Nernstian slope of $19.51 \mathrm{mV}$ per decade of activity. The observed behaviour may be attributed to the rapid exchange kinetics of the generated complex [24, 25].

It can be concluded from the characteristic performance of the proposed electrode, membrane ingredients significantly affected the Nernstian response. As seen from the Table 1, besides the importance of ionophore nature in constructing a selective membrane sensor, the sensitivity and selectivity of the ISEs are significantly affected by the composition of membrane [26]. 
Table 1 Optimization of the membrane composition to fabricate high iron (III) selective electrode

\begin{tabular}{|c|c|c|c|c|c|c|c|c|c|c|c|c|c|}
\hline \multirow[t]{2}{*}{ Sensor no. } & \multirow[t]{2}{*}{1} & \multirow[t]{2}{*}{ PVC } & \multicolumn{4}{|c|}{ Plasticizer } & \multicolumn{4}{|c|}{ Lipophilic additive } & \multirow{2}{*}{$\begin{array}{l}\text { Nernstian slope } \\
\left(\mathrm{mV} \text { decade }^{-1}\right)^{\mathrm{a}}\end{array}$} & \multirow[t]{2}{*}{$\mathrm{R}^{2}$} & \multirow{2}{*}{$\begin{array}{l}\text { Response } \\
\text { time (s) }\end{array}$} \\
\hline & & & DOP & DBP & O-NPOE & NB & KTpCIPB & NaTFPB & TDATpCIPB & NaTPB & & & \\
\hline 1 & 0 & 30.0 & & - & 69.5 & - & 0.5 & - & - & - & $4.68 \pm 0.21$ & 0.866 & $\mathrm{~N} / \mathrm{A}$ \\
\hline 2 & 3.0 & 30.0 & - & - & 66.5 & - & 0.5 & - & - & - & $16.51 \pm 0.25$ & 0.998 & 17 \\
\hline 3 & 4.0 & 30.0 & - & - & 65.5 & - & 0.5 & - & - & - & $19.51 \pm 0.10$ & 0.998 & 12 \\
\hline 4 & 5.0 & 30.0 & - & - & 64.5 & - & 0.5 & - & - & - & $24.23 \pm 0.36$ & 0.996 & 10 \\
\hline 5 & 4.0 & 30.0 & - & - & 65.5 & - & - & 0.5 & - & - & $18.14 \pm 0.41$ & 0.940 & 13 \\
\hline 6 & 4.0 & 30.0 & - & - & 65.5 & - & - & - & 0.5 & - & $12.30 \pm 0.48$ & 0.933 & 17 \\
\hline 7 & 4.0 & 30.0 & - & - & 65.5 & - & - & - & - & 0.5 & $17.77 \pm 0.35$ & 0.970 & 15 \\
\hline 8 & 4.0 & 30.0 & 65.5 & - & - & - & 0.5 & - & - & - & $14.40 \pm 0.54$ & 0.987 & 15 \\
\hline 9 & 4.0 & 30.0 & - & 65.5 & - & - & 0.5 & - & - & - & $17.40 \pm 0.45$ & 0.992 & 14 \\
\hline 10 & 4.0 & 30.0 & - & - & - & 65.5 & 0.5 & - & - & - & $11.62 \pm 0.39$ & 0.973 & 17 \\
\hline 11 & 4.0 & 30.0 & - & - & 65.8 & - & 0.2 & - & - & - & $18.34 \pm 0.26$ & 0.998 & 15 \\
\hline 12 & 4.0 & 30.0 & - & - & 65.0 & - & 1 & - & - & - & $22.17 \pm 0.33$ & 0.975 & 15 \\
\hline 13 & 4.0 & 30.0 & - & - & 64.5 & - & 1.5 & - & - & - & $24.37 \pm 0.43$ & 0.975 & 13 \\
\hline
\end{tabular}

a Average and standard deviation for triplet measurements

Therefore, effects of various parameters such as different amount of membrane ingredients as well as different type and amount of plasticizers and lipophilic additives on the potential responses of fabricated selective electrodes were investigated.

The literature surveys were in accordance with the acquired results, which indicated that the characteristic performance of the developed sensor in the term of sensitivity and selectivity affected meaningfully by changing the amount of employed ionophore [27]. In addition, it found that the membrane containing o-NPOE as a plasticizer with higher dielectric constant exhibited the best Nernstian response which is perhaps due to the facilitating the $\mathrm{Fe}^{+3}$ extraction from aqueous solution to the membrane phase $[28,29]$. Among various anion excluder used in the current work, KTpClPB demonstrated better linear range with an acceptable Nernstian slope. Lipophilic additives diminished the anionic interference effects and by decreasing the ohmic resistance of the membrane enhanced the cation extraction process $[29$, 30].

In order to improve the performance of the proposed sensor, standard internal solutions with different concentration introduced to the working electrode. The standard internal solution of $1.0 \times 10^{-3} \mathrm{M} \mathrm{Fe}\left(\mathrm{NO}_{3}\right)_{3}$ demonstrated the best electrochemical performance which used for further studies. The mentioned concentration used for equilibrating the electrodes over the night (Table 2).

\section{Sensor characterization}

To generate the calibration curve, the proposed electrode was conditioned in $1.0 \times 10^{-2} \mathrm{M}$ solution of the $\mathrm{Fe}^{3+}$ ions for $24 \mathrm{~h}$. The potential responses of fabricated sensor over a very wide concentration range of $1.0 \times 10^{-8} \mathrm{M}$ to $1.0 \times 10^{-1} \mathrm{M}$ were obtained and showed in Fig. 3A. The proposed electrode demonstrated an acceptable performance over the examined centration range. The value of $19.51 \pm 0.10 \mathrm{mV}$ per decade of activity and $8.0 \times 10^{-7} \mathrm{M}$ found as its repeatable slope and detection limit, respectively.

Repeatability of the developed sensor investigated and the obtained slope was found to be $19.51 \pm 0.10 \mathrm{mV}$ per decade of activity. Moreover, the reproducibility parameter for the proposed sensor revealed a satisfactory Nernstian slope of $19.44 \pm 0.28 \mathrm{mV}$ per decade of activity. In accordance with the SEM studies, the variation in the morphology and thickness of the fabricated polymeric membranes may result in small changes in the extraction equilibrium of target ion at the interface of sample solution aqueous layer and fabricated membrane [31].

The dynamic response time as a significant operating parameter for the performance evaluation of the developed sensor investigated and it found to be about $12 \mathrm{~s}$. The observed behaviour attributed to the fast exchange kinetics of complexation-decomplexation process

Table 2 Characterization of proposed iron (III) sensor in the term of repeatability and reproducibility

\begin{tabular}{|c|c|c|c|c|}
\hline Study & $\begin{array}{l}\text { Nernstian slope } \\
\left(\mathrm{mV} \mathrm{decade}^{-1}\right)\end{array}$ & Average & $\begin{array}{l}\text { Standard } \\
\text { deviation }\end{array}$ & $R S D$ \\
\hline Repeatability & $\begin{array}{l}19.46,19.43,19.39 \\
19.53,19.69,19.47 \\
19.58\end{array}$ & 19.51 & 0.10 & 0.52 \\
\hline Reproducibility & $\begin{array}{l}18.95,19.25,19.31 \\
19.63,19.74,19.47 \\
19.72\end{array}$ & 19.44 & 0.28 & 1.48 \\
\hline
\end{tabular}



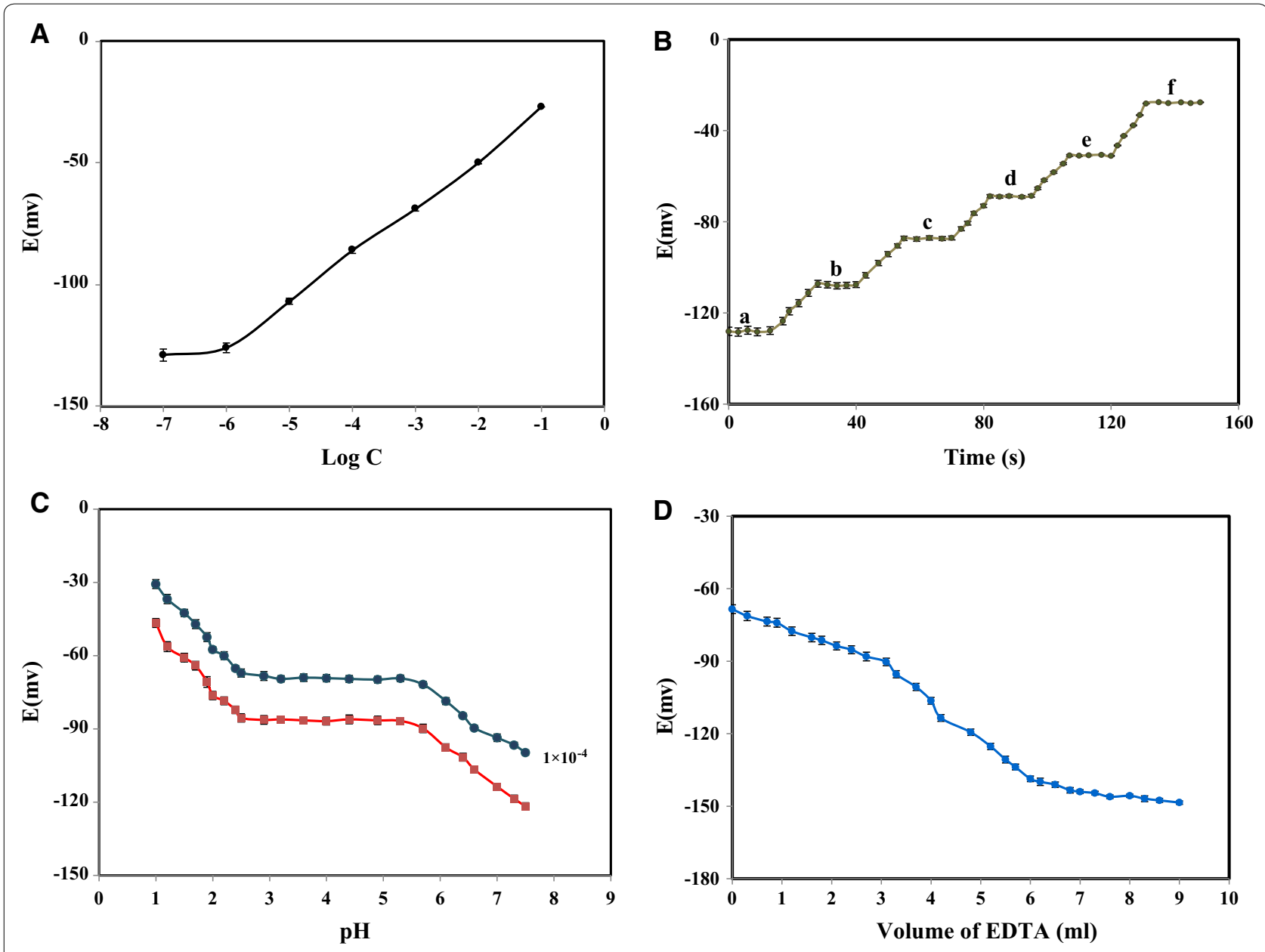

Fig. 3 The $\mathrm{Fe}^{3+}$ selective electrode characterization; A Calibration graph, $\mathbf{B}$ The dynamic response time of the for step changes in the concentration of iron solution: (a) $1.0 \times 10^{-6} \mathrm{M}$, (b) $1.0 \times 10^{-5} \mathrm{M}$, (c) $1.0 \times 10^{-4} \mathrm{M}$, (d) $1.0 \times 10^{-3} \mathrm{M}$, (e) $1.0 \times 10^{-2} \mathrm{M}$ and (f) $1.0 \times 10^{-1} \mathrm{M}$. C The pH effect of the sample solutions on the potential response. D Potentiometric titration curve of iron ion $\left(1.0 \times 10^{-3} \mathrm{M}, 50 \mathrm{~mL}\right)$ with standard EDTA solution $\left(1.0 \times 10^{-2} \mathrm{M}\right)$ using fabricated electrode based on b-18C6 as an indicator electrode at $25^{\circ} \mathrm{C}$

between investigated cation at the boundary of the polymeric selective membrane with the examined solution (see Fig. 3B).

To investigate the stability of the membrane and lifetime of the proposed sensor, they were used daily for at least $2 \mathrm{~h}$ and the obtained slopes summarized in Additional file 1 . The obtained slopes indicated that the proposed sensor could be used practically for almost 10 weeks. It found that the observed slope changed from the initial value of $19.51 \pm 0.10$ to the final value of $18.57 \pm 0.44 \mathrm{mV}$ per decade of activity after 10 weeks which probably attributed to the leaching of membrane ingredients [32].

The potential response of the proposed sensor was found to be $\mathrm{pH}$ independent over the satisfactory range of 2.5 to 5.7 (see Fig. 3C). The drift at $\mathrm{pH}$ lower than 2.5 probably attributed to the high concentration of $\mathrm{H}_{3} \mathrm{O}^{+}$ ions which cooperate in process of charge transport of the fabricated membrane. Whereas at $\mathrm{pH}$ value higher than 5.7, because of hydroxyl complexes formation the observed potential response of the developed sensor changed [33, 34].

On the other hand, the proposed sensor employed for potentiometric titration of $\mathrm{Fe}\left(\mathrm{NO}_{3}\right)_{3}$ solution by EDTA standard solution. The obtained titration curve revealed a successful titration process with a standard sigmoidal shape indicates the stoichiometry of 1:1 for the formed EDTA- $\mathrm{Fe}^{3+}$ complex (see Fig. 3D).

Separate solution method (SSM) applied to evaluate the selectivity coefficient of the proposed sensor. The applied concentration for both of analyte and interfering ions adjusted at $1.0 \times 10^{-2} \mathrm{M}$. As seen from Table 3 , the selectivity coefficient for examined interfering ions was found to be in the order of $10^{-3}$ to $10^{-5}$. The obtained 
Table 3 Proposed iron (III) sensor selectivity coefficient on separate solution method

\begin{tabular}{lll}
\hline Examined Cation & Log $K_{C s, M}^{\text {Pot }}$ & $K_{C s, M}^{\text {Pot }}$ \\
\hline $\mathrm{Fe}^{3+}$ & 1 & 0 \\
$\mathrm{~K}^{+}$ & -4.07 & $8.47 \times 10^{-5}$ \\
$\mathrm{H}^{+}$ & -3.56 & $2.74 \times 10^{-4}$ \\
$\mathrm{Na}^{+}$ & -3.93 & $1.15 \times 10^{-4}$ \\
$\mathrm{NH}_{4}{ }^{+}$ & -4.21 & $6.22 \times 10^{-5}$ \\
$\mathrm{Ag}^{+}$ & -4.18 & $6.57 \times 10^{-5}$ \\
$\mathrm{Hg}^{+}$ & -4.36 & $4.36 \times 10^{-5}$ \\
$\mathrm{Zn}^{2+}$ & -2.28 & $5.23 \times 10^{-3}$ \\
$\mathrm{Ni}^{2+}$ & -2.43 & $3.75 \times 10^{-3}$ \\
$\mathrm{Ba}^{2+}$ & -3.12 & $7.49 \times 10^{-4}$ \\
$\mathrm{Cd}^{2+}$ & -3.06 & $8.65 \times 10^{-4}$ \\
$\mathrm{Co}^{2+}$ & -2.75 & $1.78 \times 10^{-3}$ \\
$\mathrm{Cu}^{2+}$ & -2.31 & $4.86 \times 10^{-3}$ \\
$\mathrm{Mn}^{2+}$ & -4.05 & $8.94 \times 10^{-5}$ \\
$\mathrm{~Pb}^{2+}$ & -3.42 & $3.84 \times 10^{-4}$ \\
$\mathrm{Mg}^{2+}$ & -3.27 & $5.42 \times 10^{-4}$ \\
$\mathrm{Fe}^{2+}$ & -2.81 & $1.58 \times 10^{-3}$ \\
$\mathrm{Ca}^{2+}$ & -3.58 & $2.61 \times 10^{-4}$ \\
$\mathrm{Cr}^{3+}$ & -2.49 & $3.26 \times 10^{-3}$ \\
$\mathrm{Ce}^{3+}$ & -4.26 & $5.43 \times 10^{-5}$ \\
$\mathrm{La}^{3+}$ & -4.17 & $6.75 \times 10^{-5}$ \\
$\mathrm{Ti}^{3+}$ & -4.35 & $4.43 \times 10^{-5}$ \\
$\mathrm{Bi}^{3+}$ & -4.30 & $5.01 \times 10^{-5}$ \\
$\mathrm{Al}^{3+}$ & -3.10 & $7.89 \times 10^{-4}$ \\
\hline
\end{tabular}

values showed that in comparison to the earlier described iron (III) sensor a considerable improvement observed [2, $3]$.

\section{Membrane characterization}

In the current work the FT-IR investigation employed as qualitative technique to evaluate the prepared membrane in the term of lifetime (see Fig. 4I). Evidently, the existence of b-18C6 in membrane composition confirmed by the strong absorption band appeared in $1280 \mathrm{~cm}^{-1}$ frequency due to $\mathrm{C}-\mathrm{O} \mathrm{sp}^{3}$ stretching. The presence of o-NPOE deduced by its two strong absorption bands associated with the nitro functional group $\left(\mathrm{NO}_{2}\right)$ including an asymmetric and a symmetric stretching vibration appear at $1526 \mathrm{~cm}^{-1}$ and $1353 \mathrm{~cm}^{-1}$, respectively. Moreover, the observed absorption bands at $745 \mathrm{~cm}^{-1}$ and $1081 \mathrm{~cm}^{-1}$ which related to $\mathrm{C}-\mathrm{Cl}$ and $\mathrm{B}-\mathrm{C}$ stretching, respectively, confirmed the presence of lipophilic additive KTpClPB. Lastly, the presence of PVC as an inert matrix of the membrane confirmed by gauche absorption bands observed in $669 \mathrm{~cm}^{-1}$ region. On the other hand, two absorption bands in $1608 \mathrm{~cm}^{-1}$ and $1467 \mathrm{~cm}^{-1}$ frequencies attributed to aromatic stretching of $\mathrm{C}=\mathrm{O}$, one absorption band around $2859 \mathrm{~cm}^{-1}$ related to $\mathrm{C}-\mathrm{H}$ $\mathrm{sp}^{3}$ stretching, and stretching of $=\mathrm{C}-\mathrm{H} \mathrm{sp}{ }^{2}$ appears at $2927 \mathrm{~cm}^{-1}$ are some general absorption bands for all membrane ingredients. The wide absorption band related to $\mathrm{O}-\mathrm{H}$ stretching observed in $3434 \mathrm{~cm}^{-1}$ owing to the membrane saturation in the aqueous medium. As it is




illustrated in Fig. 4II, the evaluation of the spectra related to the employed membranes demonstrated that no significant change observed in the membrane composition which proved its long lifetime and stability.

To examine the preferred coordination of $\mathrm{Fe}^{3+}$ ions by b-18C6, UV-Vis spectroscopy analysis carried out. Literature surveys revealed that the ionic species with higher affinity to form complex, resulted in more significant variation in appearance and position of the obtained spectrum [35]. The UV spectroscopy analysis practiced for the b-18C6, $\mathrm{Fe}^{3+}$ cation and their 1:1 mixture and demonstrated in Fig. 5. As seen, the ionophore and $\mathrm{Fe}^{3+}$ displayed two separate maximum absorptions at $273 \mathrm{~nm}$ and $215 \mathrm{~nm}$, respectively. Whereas for their mixture, the intensity of the observed absorption band increased slightly and shifted to $282 \mathrm{~nm}$. The observed behaviour attributed to the preferred complexation between b-18C6 and $\mathrm{Fe}^{3+}$ cation.

To image the surface characteristics of the proposed selective membrane such as fouling and swelling, SEM investigations were carried out at $10 \mu \mathrm{m}$ magnifications [36].

As seen from Fig. 6, lack of ionophore in the prepared membrane resulted in a physically tight structure, however in the case of its adding to the membrane a physically permeable and loose structure observed. Furthermore, due to the daily usage of the proposed electrode, the membrane shows a swollen structure over 10 weeks. On the other hand, the surface of the membrane completely covered by contaminated sediments after daily usage over 20 weeks and it lost its ability.

\section{Sensor validation}

Drinking tap water and hospital wastewater sample after treatment through the electrocoagulation process



Fig. 5 UV-Vis absorption spectra: (A) $1.0 \times 10^{-3} \mathrm{M} \mathrm{Fe}^{3+}$, (B) $1.0 \times 10^{-3}$ $\mathrm{M}$ b-18C6 and (C) mixture of ionophore and cation used as environmental samples to evaluate the analytical applicability and accuracy of the proposed sensor. As seen from Table 4, acceptable compliance observed between the results achieved by the proposed sensor and the data acquired from atomic absorption spectrometry (AAS).

\section{Computational analysis}

The adsorption process of $\mathrm{Fe}^{+3}$ cationic species by b-18C6 theoretically investigated employing the DFT/ B3LYP computational level with the 6-311G basis set using the Gaussian 09 program package. The following equation expressed the calculation procedure of $E_{a d s}$ (adsorption energy) between $\mathrm{Fe}^{+3}$ and b-18C6:

$$
\mathrm{E}_{\mathrm{ads}}=\mathrm{E}_{(\text {complex })}-\mathrm{E}_{(\mathrm{b}-18 \mathrm{C} 6)}-\mathrm{E}_{\left(\mathrm{Fe}^{+3}\right)}
$$

where $\mathrm{E}_{\text {(complex) }}, \mathrm{E}_{(\mathrm{b}-18 \mathrm{C} 6)}$ and $\mathrm{E}_{(\mathrm{Fe})}^{+3}$ denote the total energy of the formed complex, the total energy of b-18C6, and the total energy of $\mathrm{Fe}^{+}$cationic species, respectively.

According to the calculated adsorption energy of $-19.04 \mathrm{eV}$ which is a large negative value can be concluded that the optimized structure of the formed complex is stable. By evaluating the gap of energy between the highest occupied molecular orbital (HOMO) and the lowest unoccupied molecular orbital (LUMO) the molecular electrical conductance properties can be described. The HOMO-LUMO diagrams and the energies of the formed complex and b-18C6 demonstrated in Fig. 7. The HOMO-LUMO energy gap of $0.107 \mathrm{eV}$ found for the formed complex which indicated adequate electron conductivity due to the low difference between molecular orbitals. Moreover, the obtained result provided a measure of structural stability properties [37].

Natural bond orbital (NBO) analysis carried out to study the strength and nature of the intermolecular interactions of the formed complex at the same level of theory. The obtained results including some important orbital interactions of oxygen atoms which contributed in donor-acceptor interactions with $\mathrm{LP}^{*}(\mathrm{Fe})$ as well as their second-order perturbation stabilization energies $E^{(2)}$ summarized in Table 5. The achieved results highlighted that iron prefers to participate in the complex formation process as the acceptor while the aromatic ring and oxygen prefer to participate as donors through coordinate bands.

The charge distribution on the structure of the formed complex demonstrated in Fig. 8. According to the calculated value in Table 5, for second-order perturbation stabilization energies, oxygen atom number 41 has the largest $\mathrm{E}^{(2)}$ energy and highest interaction level with iron (III) cation. The charges of selected oxygen atoms and iron atom summarized in Additional file 2. 


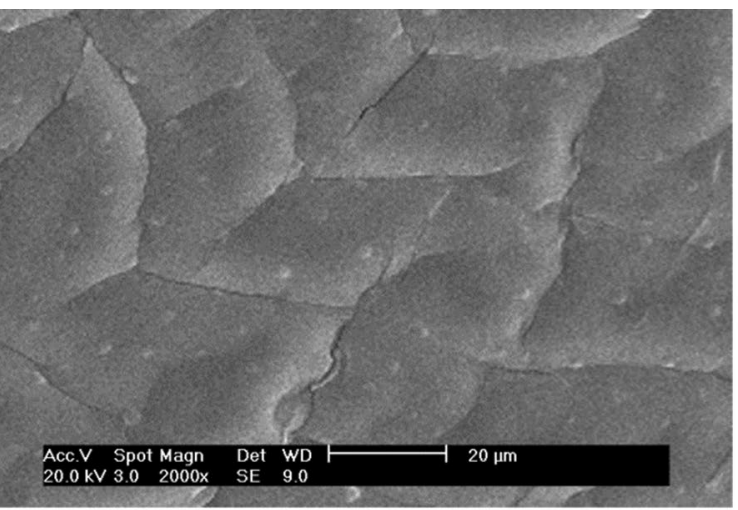

a

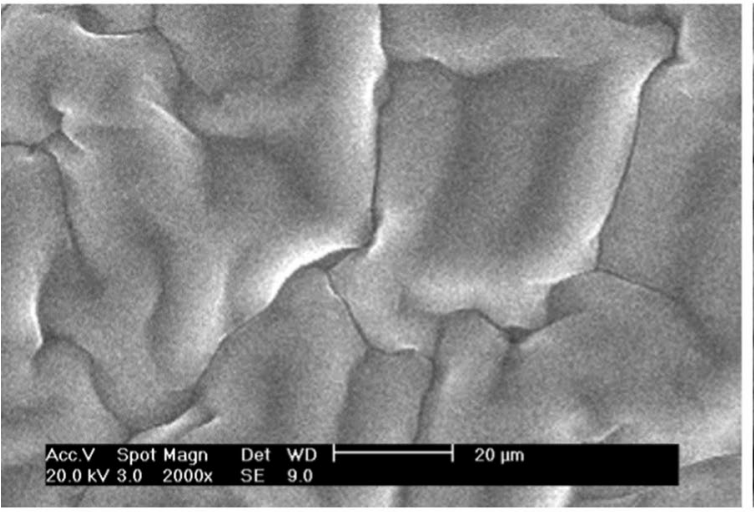

C

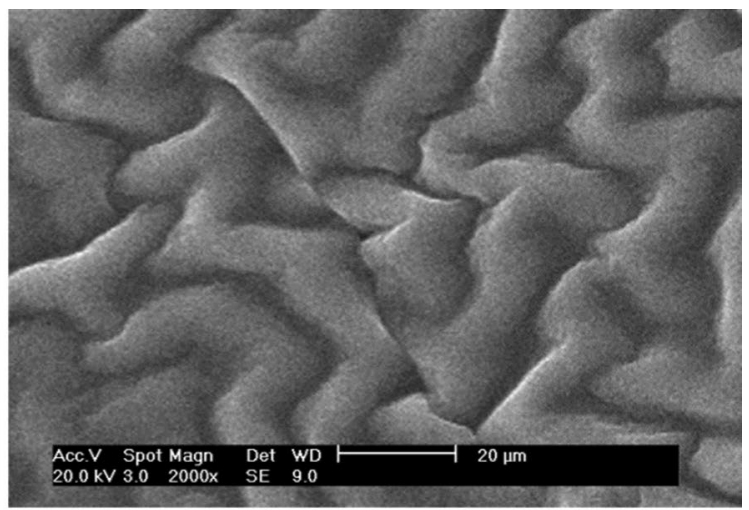

b

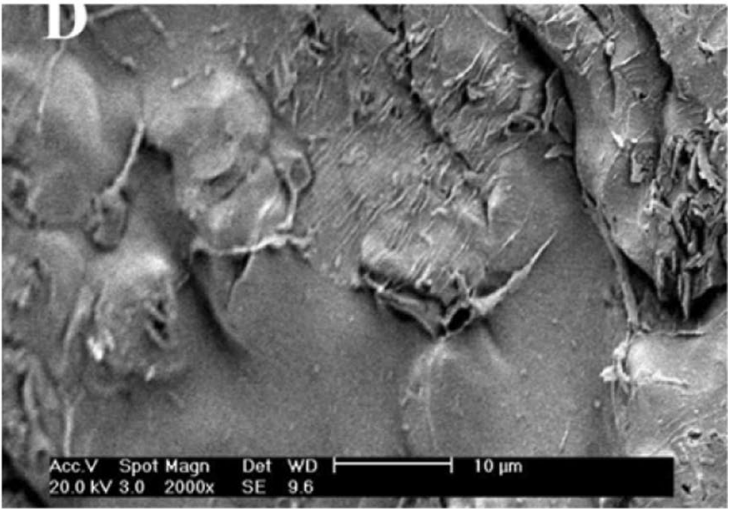

d

Fig. 6 Scanning electron microphotographs (SEM) of iron (III) selective PVC membrane at $10 \mu \mathrm{m}$ magnifications: a membrane without ionophore that conditioned for 1 day, $\mathbf{b}$ membrane with ionophore that conditioned for 1 day, $\mathbf{c}$ membrane that conditioned for 10 weeks, and $\mathbf{d}$ membrane that conditioned for 20 weeks and used daily over the mentioned period

Table 4 Determination of iron (III) amount of real samples using standard addition technique

\begin{tabular}{|c|c|c|c|c|}
\hline \multirow[t]{2}{*}{ Sample } & \multirow[t]{2}{*}{ Amount added (ppm) } & \multicolumn{2}{|c|}{ Concentration of $\mathrm{Fe}^{3+}$ ions (ppm) } & \multirow[t]{2}{*}{ Recovery (\%) } \\
\hline & & ISE method ${ }^{a}$ & AAS method ${ }^{a}$ & \\
\hline \multirow[t]{6}{*}{ Drinking tap water } & - & $<$ Limit of detection & $<$ Limit of detection & $\mathrm{N} / \mathrm{A}$ \\
\hline & 5.00 & $5.21 \pm 0.32$ & $5.08 \pm 0.11$ & 102.5 \\
\hline & 10.00 & $10.03 \pm 0.19$ & $10.13 \pm 0.15$ & 99.0 \\
\hline & 15.00 & $15.32 \pm 0.41$ & $15.25 \pm 0.42$ & 100.4 \\
\hline & 25.00 & $25.39 \pm 0.24$ & $25.10 \pm 0.28$ & 101.1 \\
\hline & 40.00 & $39.85 \pm 0.36$ & $40.37 \pm 0.17$ & 98.7 \\
\hline \multirow[t]{4}{*}{ Treated hospital waste water } & - & $14.11 \pm 0.21$ & $13.73 \pm 0.21$ & 102.7 \\
\hline & 10.00 & $23.85 \pm 0.34$ & $23.52 \pm 0.32$ & 101.4 \\
\hline & 20.00 & $33.21 \pm 0.19$ & $33.84 \pm 0.22$ & 98.1 \\
\hline & 30.00 & $43.79 \pm 0.35$ & $43.44 \pm 0.36$ & 100.8 \\
\hline
\end{tabular}

\footnotetext{
a Average and standard deviation for triplet measurements
} 

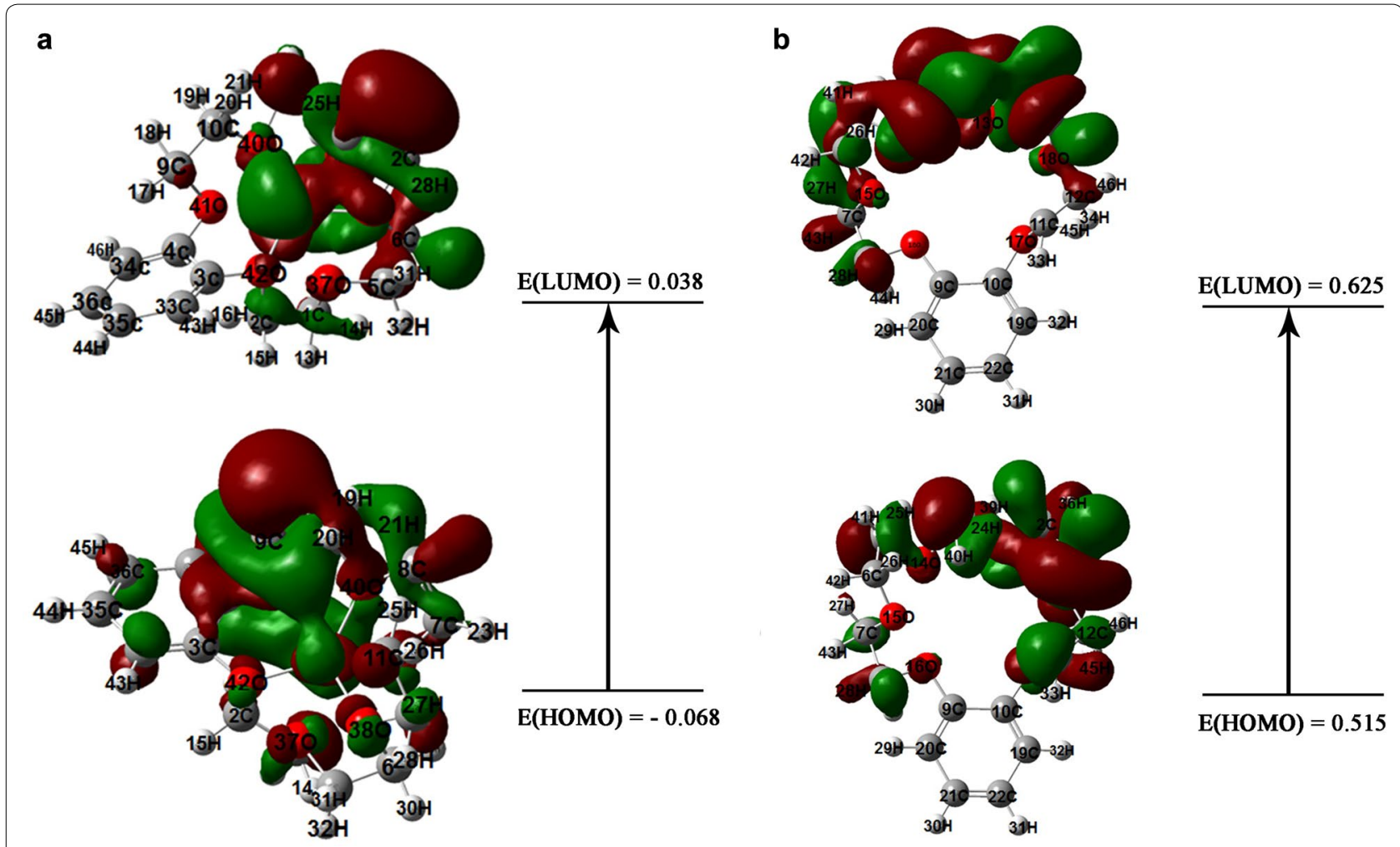

Fig. $7 \mathrm{HOMO}$ and LUMO compositions of the frontier orbital for $\mathbf{a}$ formed complex and $\mathbf{b}$ on benzo-18-crown-6 ionophore

\begin{tabular}{|c|c|c|}
\hline Donor atom-number & Acceptor & $\begin{array}{l}\mathrm{E}(2) \\
\text { (kcal/ } \\
\mathrm{mol})\end{array}$ \\
\hline $0-37$ & $L P^{*} \mathrm{Fe}$ & 0.36 \\
\hline O-38 & $L P^{*} \mathrm{Fe}$ & 0.73 \\
\hline 0-39 & $L P^{*} \mathrm{Fe}$ & 0.81 \\
\hline $0-40$ & $L P^{*} \mathrm{Fe}$ & 0.72 \\
\hline O-41 & $\mathrm{LP}^{*} \mathrm{Fe}$ & 1.68 \\
\hline $0-42$ & $\mathrm{LP}^{*} \mathrm{Fe}$ & 0.21 \\
\hline
\end{tabular}

\section{Comparison of reported works with proposed sensor}

The characteristics performance of the proposed sensor in comparison to the early described $\mathrm{Fe}^{3+}$ ion-selective sensors summarized in Table 6. The developed sensor in the current work revealed better characteristics in the terms of dynamic range, the lower limit of detection and response time. Since the potential response of the fabricated sensor in the current work was independent of the solution $\mathrm{pH}$ over a reasonable range, it could be employed as promising tool for analysis of iron (III) concentration in environmental fields.

\section{Conclusions}

The developed highly $\mathrm{Fe}^{3+}$ selective electrode in the current work revealed an acceptable performance as a diagnostic tool for the evaluation of trace amount of iron (III) in drinking tap water and treated hospital wastewater samples. The characteristic performance of the proposed sensor is favorable compared to previously developed iron (III) potentiometric sensors. The theoretical studies through density functional theory confirmed the preferred coordination between $\mathrm{Fe}^{3+}$ cation and b-18C6. The obtained computational results established their stable and selective interaction. 


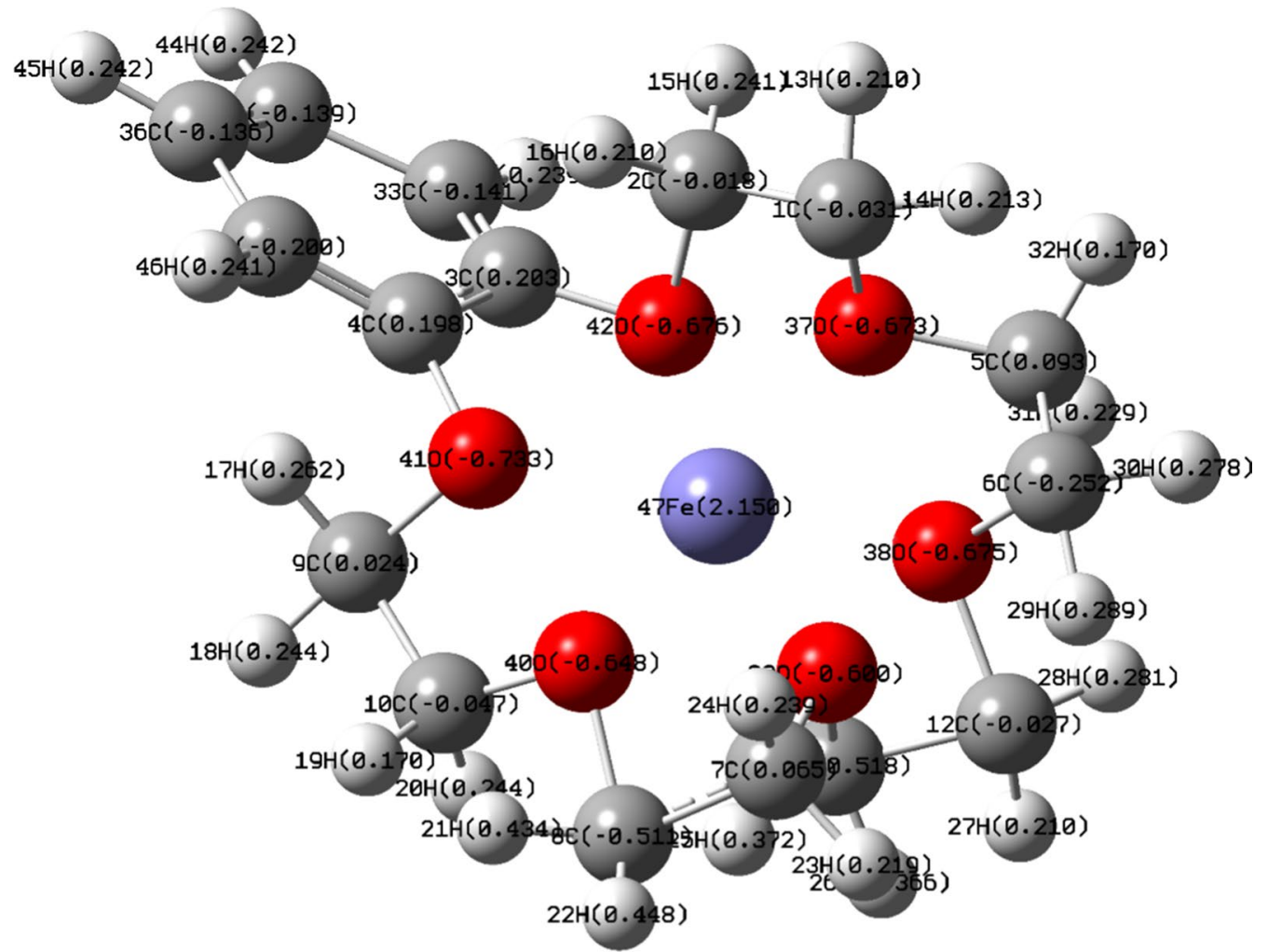

Fig. 8 Charge distribution of the optimized structure of formed complex

Table 6 Comparison of the characteristics performance of fabricated iron (III) selective electrode in this study with reported iron (III) electrodes

\begin{tabular}{|c|c|c|c|c|c|c|}
\hline lonophore & Working range $(\mathrm{M})$ & Detection limit (M) & Slope $\left(m V\right.$ decade $\left.^{-1}\right)$ & $\begin{array}{l}\text { Response } \\
\text { time (s) }\end{array}$ & $\mathrm{pH}$ & $\overline{\text { Refs. }}$ \\
\hline Bis-bidentate Schiff (BBS) & $1.0 \times 10^{-7}$ to $1.0 \times 10^{-2}$ & $7.4 \times 10^{-8}$ & $19.3 \pm 0.6$ & $<15$ & $1.9-5.1$ & [2] \\
\hline$\mu$-bis(tridentate) & $6.3 \times 10^{-6}$ to $1.0 \times 10^{-1}$ & $5.0 \times 10^{-6}$ & 20.0 & 15 & $3.5-5.5$ & [1] \\
\hline $\begin{array}{l}\text { 2-[(2-hydroxy-1-propenyl-buta-1,3-dienylimino)- } \\
\text { methyl]-4-p-tolylazo-phenol [HPDTP] }\end{array}$ & $3.5 \times 10^{-6}$ to $4.0 \times 10^{-2}$ & $(2.5 \pm 0.5) \times 10^{-6}$ & $28.5 \pm 0.5$ & 15 & $4.5-6.5$ & [4] \\
\hline $\begin{array}{l}\text { 4-amino-6-methyl-3-methylmercapto-1,2,4- } \\
\text { triazin-5-one (AMMTO) }\end{array}$ & $1.0 \times 10^{-6}$ to $1.0 \times 10^{-1}$ & $6.8 \times 10^{-7}$ & $19.4 \pm 0.5$ & $<15$ & $2.2-4.8$ & [9] \\
\hline $\begin{array}{l}\mathrm{N}\left(2 \text { hydroxyethyl)ethylenediamine- } \mathrm{N}, \mathrm{N}^{\prime} \text {, }\right. \\
\mathrm{N}^{\prime \prime} \text {-triacetic acid (NTA) }\end{array}$ & $1.0 \times 10^{-9}$ to $1.0 \times 10^{-2}$ & $3.0 \times 10^{-10}$ & $19.5 \pm 0.4$ & 10 & $1.8-4.5$ & [3] \\
\hline Current study & $1.0 \times 10^{-6}$ to $1.0 \times 10^{-1}$ & $8.0 \times 10^{-7}$ & $19.51 \pm 0.10$ & 12 & $2.5-5.7$ & - \\
\hline
\end{tabular}

\section{Supplementary information}

Supplementary information accompanies this paper at https://doi. org/10.1186/s13065-019-0648-x.

Additional file 1. The life time of the proposed iron (III) sensor.

Additional file 2. Charges of oxygen and iron atoms in the formed complex.

\section{Acknowledgements}

The authors express their appreciation to Pharmaceutics research centre and Student research committee both affiliated to Kerman University of Medical Sciences, Kerman, Iran, and Shahid Beheshti University of Medical Sciences, Tehran, Iran for supporting the current work.

Authors' contributions

SB performed the experiments. AM performed the simulations and computational studies. AM and MJ provided the chemicals and conceived the idea. SA 
supervised the study and write the manuscript. All authors read and approved the final manuscript.

\section{Funding}

Not applicable.

\section{Availability of data and materials}

All data and materials could be available upon the request.

\section{Competing interests}

All authors declare that they have no competing or conflict of interests.

\section{Author details}

${ }^{1}$ Student research committee, Kerman University of Medical Sciences, Kerman, Iran. ${ }^{2}$ Department of Environmental Health Engineering, School of Public Health, Bam University of Medical Sciences, Bam, Iran. ${ }^{3}$ Pharmaceutics Research Center, Institute of Neuropharmacology, Kerman University of Medical Sciences, P.O. Box: 76175-493, 76169-11319 Kerman, Iran. ${ }^{4}$ Food, Drug and Cosmetics Safety Research Center, Kerman University of Medical Sciences, Kerman, Iran. ${ }^{5}$ Department of Environmental Health Engineering, School of Public Health, Shahid Beheshti University of Medical Sciences, Tehran, Iran. ${ }^{6}$ Department of Environmental Health Engineering, School of Public Health, Kerman University of Medical Sciences, Kerman, Iran. ${ }^{7}$ Department of Chemistry, Faculty of Science, Ferdowsi University of Mashhad, Mashhad, Iran.

\section{Received: 11 July 2019 Accepted: 1 November 2019}

Published online: 18 November 2019

\section{References}

1. Gupta VK, Jain A, Agarwal S, Maheshwari G (2007) An iron (III) ion-selective sensor based on a $\mu$-bis (tridentate) ligand. Talanta 71:1964-1968

2. Zamani HA, Ganjali MR, Salavati-Niasari M (2008) Fabrication of an iron (III)-selective PVC membrane sensor based on a bis-bidentate Schiff base ionophore. Trans Met Chem 33:995-1001

3. Zamani HA, Hamed-Mosavian MT, Hamidfar E, Ganjali MR, Norouzi P (2008) A novel iron (III)-PVC membrane potentiomeric sensor based on $\mathrm{N}$-(2-hydroxyethyl) ethylenediamine-N, N', N"-triacetic acid. Mater Sci Eng, C 28:1551-1555

4. Mashhadizadeh MH, Shoaei IS, Monadi N (2004) A novel ion selective membrane potentiometric sensor for direct determination of Fe(III) in the presence of Fe(II). Talanta 64:1048-1052

5. Lunvongsa S, Oshima M, Motomizu S (2006) Determination of total and dissolved amount of iron in water samples using catalytic spectrophotometric flow injection analysis. Talanta 68:969-973

6. Masawat P, Harfield A, Srihirun N, Namwong A (2017) Green determination of total iron in water by digital image colorimetry. Anal Lett 50:173-185

7. Samadi A, Amjadi M (2016) Halloysite nanotubes as a new adsorbent for solid phase extraction and spectrophotometric determination of iron in water and food samples. J Appl Spectrosc 83:422-428

8. Peng B, Chen G, Li K, Zhou M, Zhang J, Zhao S (2017) Dispersive liquidliquid microextraction coupled with digital image colorimetric analysis for detection of total iron in water and food samples. Food Chem 230:667-672

9. Pooyamanesh MJ, Zamani HA, Rajabzadeh G, Ganjali MR, Norouzi P (2007) Fe (III) lon-selective membrane electrode based on 4-amino-6-methyl3-methylmercapto-1, 2, 4-triazin-5-one. Anal Lett 40:1596-1609

10. Shen J, Gagliardi S, McCoustra MRS, Arrighi V (2016) Effect of humic substances aggregation on the determination of fluoride in water using an ion selective electrode. Chemosphere 159:66-71

11. Gupta VK, Jain AK, Khayat MA, Bhargava SK, Raisoni JR (2008) Electroanalytical studies on cobalt (II) selective potentiometric sensor based on bridge modified calixarene in poly (vinyl chloride). Electrochim Acta 53:5409-5414

12. Gupta VK, Jain AK, Kumar P, Agarwal S, Maheshwari G (2006) Chromium(III)-selective sensor based on tri-o-thymotide in PVC matrix. Sens Actuat B 113:182-186

13. Ceresa A, Bakker E, Hattendorf B, Günther D, Pretsch E (2001) Potentiometric polymeric membrane electrodes for measurement of environmental samples at trace levels: new requirements for selectivities and measuring protocols, and comparison with ICPMS. Anal Chem 73:343-351

14. Ion AC, Bakker E, Pretsch E (2001) Potentiometric Cd2 +-selective electrode with a detection limit in the low ppt range. Anal Chim Acta 440:71-79

15. Balderas-Hernández P, Roa-Morales G, Ramírez-Silva MT, Romero-Romo M, Rodríguez-Sevilla E, Esparza-Schulz JM, Juárez-Gómez J (2017) Effective mercury(II) bioremoval from aqueous solution, and its electrochemical determination. Chemosphere 167:314-321

16. Ramanjaneyulu PS, Singh P, Sayi YS, Chawla HM, Ramakumar KL (2010) Ion selective electrode for cesium based on 5-(4'-nitrophenylazo) 25, 27-bis (2-propyloxy) 26, 28-dihydroxycalix [4] arene. J Hazard Mater $175: 1031-1036$

17. Chen L, Ju H, Zeng X, He X, Zhang Z (2001) Cesium selective electrodes based on novel double flexible spacers bridged biscalix [4] arenes. Anal Chim Acta 447:41-46

18. Ahmadzadeh S, Rezayi M, Karimi-Maleh H, Alias Y (2015) Conductometric measurements of complexation study between 4-Isopropylcalix [4] arene and $\mathrm{Cr} 3$ + cation in THF-DMSO binary solvents. Measurement 70:214-224

19. Faridbod F, Ganjali MR, Dinarvand R, Norouzi P (2008) Developments in the field of conducting and non-conducting polymer based potentiometric membrane sensors for ions over the past decade. Sensors 8:2331-2412

20. Comeau B: plasticizer alternatives for use in polymer membrane ion selective electrodes. Tufts University; 2008

21. Radu A: Experimental and theoretical insights in the improvement of the detection limit of ion selective electrodes. Auburn Alabama, 2005

22. Bakker E, Xu A, Pretsch E (1994) Optimum composition of neutral carrier based pH electrodes. Anal Chim Acta 295:253-262

23. Oehme M, Simon W (1976) Microelectrode for potassium ions based on a neutral carrier and comparison of its characteristics with a cation exchanger sensor. Anal Chim Acta 86:21-25

24. Gupta VK, Mergu N, Kumawat LK, Singh AK (2015) Selective naked-eye detection of magnesium (II) ions using a coumarin-derived fluorescent probe. Sens Actuators B 207:216-223

25. Gupta N, Singh AK, Bhardwaj S, Singhal D (2015) Electroanalytical studies of chromone based ionophores for the selective determination of arsenite ion. Electroanalysis 27:1166-1175

26. Mittal SK, Kumar SK, Sharma HK (2004) PVC-based dicyclohexano18-crown-6 sensor for La (III) ions. Talanta 62:801-805

27. Bakker E, Buhlmann P, Pretsch E (1997) Carrier-based ion-selective electrodes and bulk optodes. 1. General characteristics. Chem Rev 97:3083-3132

28. Ammann D, Morf WE, Anker P, Meier PC (1983) Neutral carrier based ionselective electrodes. Ion-Selective Electrode Rev 5:1

29. Choi Y, Kim H, Lee JK, Lee SH, Lim HB, Kim JS (2004) Cesium ion-selective electrodes based on 1, 3-alternate thiacalix [4] biscrown-6, 6. Talanta 64:975-980

30. Zamani HA, Rajabzadeh G, Ganjali MR (2006) Highly selective and sensitive chromium(III) membrane sensors based on 4-amino-3-hydrazino6-methyl-1,2,4-triazin-5-one as a new neutral ionophore. Sens Actuators B 119:41-46

31. Kamal A, Kumar N, Bhalla V, Kumar M, Mahajan RK (2014) Rhodaminedimethyliminocinnamyl based electrochemical sensors for selective detection of iron (II). Sens Actuators B 190:127-133

32. Kamal A, Kumar K, Kumar V, Mahajan RK (2014) Electrochemical and chromogenic sensors based on ferrocene appended chalcone for selective quantification of copper (II). Electrochim Acta 145:307-313

33. Ahmadzadeh S, Asadipour A, Yoosefian M, Dolatabadi M (2017) Improved electrocoagulation process using chitosan for efficient removal of cefazolin antibiotic from hospital wastewater through sweep flocculation and adsorption: kinetic and isotherm study. Desal Water Treat 92:160-171

34. Ahmadzadeh S, Dolatabadi M (2018) Modeling and kinetics study of electrochemical peroxidation process for mineralization of bisphenol $\mathrm{A}$; a new paradigm for groundwater treatment. J Mol Liq 254:76-82

35. Singh AK, Gupta VK, Gupta B (2007) Chromium (III) selective membrane sensors based on Schiff bases as chelating ionophores. Anal Chim Acta 585:171-178 
36. Bakker E, Diamond D, Lewenstam A, Pretsch E (1999) Ion sensors: current limits and new trends. Anal Chim Acta 393:11-18

37. Ahmadzadeh S, Rezayi M, Kassim A, Aghasi M (2015) Cesium selective polymeric membrane sensor based on p-isopropylcalix [6] arene and its application in environmental samples. RSC Adv 5:39209-39217

\section{Publisher's Note}

Springer Nature remains neutral with regard to jurisdictional claims in published maps and institutional affiliations.
Ready to submit your research? Choose BMC and benefit from:

- fast, convenient online submission

- thorough peer review by experienced researchers in your field

- rapid publication on acceptance

- support for research data, including large and complex data types

- gold Open Access which fosters wider collaboration and increased citations

- maximum visibility for your research: over 100M website views per year

At BMC, research is always in progress.

Learn more biomedcentral.com/submissions 